research became the understanding of the origins of farming. But even then special recovery methods were not normally used for such materials, nor was very serious thought given to the effect of such techniques as were used on the quality or nature of the resultant data.

Perhaps the first systematic attempt to develop, on a deeply stratified site, recovery methods appropriate to such materials came in 1963 in the excavations at the early farming site of $\mathrm{Ali}$ Kosh in south-western Iran. All the excavated material was screened through a sieve, and selected samples were subjected to a water flotation process to recover carbonized grain. The flotation method for archaeological materials was first reported in the United States (Struever, Amer. Antiq., 33, 353 ; 1965), and modified at Ali Kosh by Hans Helbaek. As the excavators of Ali Kosh aptly commented: "While most Near Eastern archaeologists have dug for buildings and incidentally recovered a few seeds in the process, we dug for seeds and incidentally recovered a few frag. ments of buildings in the process" (Hole, Flannery and Neely, Prehistory and Human Ecology of the Deh Luran Plain, University of Michigan, Ann Arbor, 1969, p. 4).

Systematic sieving of a column sample is likewise an American innovation: it has for some time been used routinely on the shell middens of the Californian Indians, which are little more than mounds of discarded food refuse (Meighan et al., Amer. Antiq., 24, 1 ; 1958), but only recently has it been applied coherently and systematically to a wider range of sites. In particular, water sieving has proved a particularly rapid and efficient means of recovering material, and a number of "machines" which systematize and speed the processes of flotation and sieving of the soil have come into use in the past two or three years (French, Anatol. Stud., 21, 59 ; 1971). They have been used to good effect by Dr David French, Director of the British Institute of Archaeology at Ankara in the institute's rescue excavations in the Keban area of eastcentral Turkey, and on his important and very early neolithic site, Can Hasan III.

It is now becoming clear, however, that the real significance of these uses is not simply in the increased recovery of material, but principally in the increased reliability of the data so

obtained as a basis for the quantitative reconstruction of early diet or, in the case of small artefacts, for a quantitatively valid assessment of the cultural equipment at the site. Several contributions to Papers in Economic Prehistory (edited by Higgs, University Press, Cambridge, 1972) make this point with great force. Two in particular, by Payne, demonstrate the great vulnerability of archaeological data to sample bias. Already the circumstances of burial and of preservation cause serious distortion: Payne has now shown clearly the severe bias that is introduced by considering material recovered by hand during excavation - animal bones for instance. Systematic recovery by sieving radically alters not only the quantities recovered, but the proportions of one species to another, whose estimation is, of course, the object of the exercise. Dennell, in the same volume, in discussing the interpretation of plant remains, shows how the results obtained depend greatly on the type of deposit recovered, whether from floors or middens, and emphasizes that only carefully controlled recovery procedures will permit of any distinction between these. Few archaeologists in the future are likely to accept as reliable any assertion

\title{
Function of Nuclear RNP Particles
}

THE presence of ribohomopolymer regions in nuclear heterogenous high molecular weight RNA (HnRNA) and in cytoplasmic mRNA has been recognized for some time. Although it is known that the synthesis of ribohomopolymers is a post-transcriptional event, the precise timing and location of the process are uncertain. The function of these homopolymer regions is also unknown, although it has been suggested that they have a role in the processing of HnRNA to produce cytoplasmic mRNA. It is satisfying, then, to read the report of Niessing and Sekeris in next Wednesday's Nature New Biology (May 2) which describes two enzymatic activities and a ribohomopolymer synthetase activity in rat liver nuclear ribonucleoprotein (RNP) particles.

Niessing and Sekeris investigated these enzymatic activities in vitro using isolated $30 \mathrm{~S}$ nuclear RNP particles. Optimal incorporation of ATP, CTP, GTP and UTP into homopolymers was achieved at $15 \mathrm{mM} \mathrm{Mn}^{2+}$. ATP incorporation into poly (A) was also obtained at $5 \mathrm{mM} \mathrm{Mn}^{2+}$ and at $12 \mathrm{mM} \mathrm{Mg}^{2+}$. These three enzymatic activities have about early diet that is not based, at least in part, on the results of controlled sievings, themselves carefully interpreted.

Column sampling, for long regarded as an inadequate means of archaeological recovery, is in consequence of such studies again being found useful. It is, of course, a well established procedure in pollen analysis, and has previously been used for this purpose on archaeological sites lying in peat (Clark and Godwin, Antiquity, 36, 10 ; 1962). And archaeologists are now coming to realize that an understanding of the processes by which the site was formed, geomorphologically, can make a significant contribution. This is now seen to apply, not simply to the great depths of natural deposit which often cover palaeolithic sites and which have for long been studied by Quaternary geologists, but to the cultural levels themselves which were formed as the result of natural as well as human activities. The tell mounds of the Near East, for instance, have never been investigated geologically or geomorphologically, although they are very prominent features of the landscape. The problem of their formation has now been tackled by Davidson (Archaeometry, 15, 143; 1973) in an article which will surely distinct $p \mathrm{H}$ optima. Examination of the reaction products by high voltage electrophoresis of alkaline hydrolysates indicates that the ribohomopolymers are not synthesized de novo but are formed by the successive addition of nucleotides to a pre-existing polynucleotide. Homopolymer formation is independent of DNA but addition of rat liver nuclear RNA stimulates the reaction three-fold. Treatment of RNP particles with RNase eliminates ribohomopolymer formation. Thus it is probable that the HnRNA contained in the RNP particles serves as a primer for synthesis of ribohomopolymers. Inhibitors of transcription have no effect on the enzymatic activities of the homopolymer.

Niessing and Sekeris have previously found in the protein moiety of RNP particles an enzyme which cleaves HnRNA. The discovery now in RNP particles of ribohomopolymer synthesizing enzymes which operate at a posttranscriptional stage independently of DNA points strongly to the role of RNP particles as the sites of cleavage and further processing of HnRNA to produce mRNA in its cytoplasmic form. 